Enn Kasak

\title{
ANCIENT ASTROLOGY AS A COMMON ROOT FOR SCIENCE AND PSEUDO-SCIENCE
}

This is a copy of the article from printed version of electronic journal

\section{Folklore Vol. 15}

ISSN 1406-0957

Editors Mare Kõiva \& Andres Kuperjanov

Published by the Folk Belief and Media Group of ELM

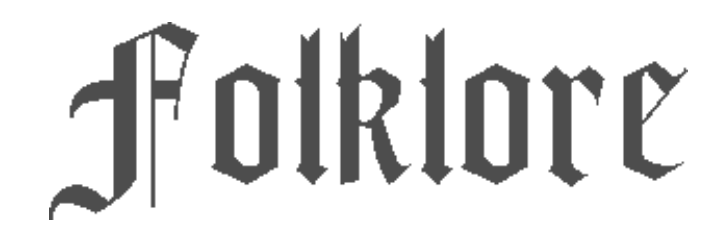

\section{Electronic Journal of Folklore}

Electronic version ISSN 1406-0949 is available from http://haldjas.folklore.eelfolklore

It's free but do give us credit when you cite!

(C) Folk Belief and Media Group of ELM, Andres Kuperjanov

\section{Tartu 2000}




\section{ANCIENT ASTROLOGY AS A COMMON ROOT FOR SCIENCE AND PSEUDO- SCIENCE}

\section{Enn Kasak}

The early history of astrology is closely interrelated with the history of astronomy. Both may be studied separately, but the result may prove one-sided and one may fail to notice things of great consequence. The history of ancient astronomy must be treated jointly with the history of astrology, whose contribution to the history of science has often been underestimated. This situation has begun to change only recently. The number of academic publications suggests that in addition to ancient philosophy, mathematics and astronomy, more and more attention is being paid to ancient astrology, which has played an important role in the history of human thought.

\section{THE CONCEPT OF ASTRONOMY}

The term 'astrology' ( $\alpha \sigma \tau \rho o \lambda o \gamma i \alpha$ - 'science of stars' or 'study of stars') derives from Ancient Greek and is made up of two words - $\dot{\alpha} \sigma \tau \eta \rho$ (asteer) 'star' or 'constellation' and an intricate form $\lambda o$ ó (logos) that may denote very different things - reasoning, intellect, story, word, etc., that we, perhaps, may here translate as 'study'. Although the names of several modern sciences such as philology, geology and biology end with the same combining form, we cannot consider astrology as the 'science of stars', which in fact is the general definition of astronomy. The term 'astronomy' is formed with the word vó $\mu$ ऽ (nomos), or 'law', thus the direct translation of 'astronomy' is the 'law of stars'. Before the Middle Ages the word 'astrology' was often used to designate the science of stars, sometimes the above terms were used synonymously. The modern definition of astrology describes it as a discipline that characterises and foretells things and events according to the configuration of celestial bodies, and presently does not include it among sciences proper. Therefore, to avoid confusion, in the following we will use the terms astrology and astronomy in the modern sense, even though they may conflict 
in form with source texts. For example, instead of our term 'astrology' Tetrabiblos by Claudius Ptolemy uses the expression $\tau o ́$ i $\delta$ '

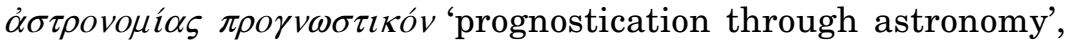
whereas both $\dot{\alpha} \sigma \tau \rho$ ovouí and $\dot{\alpha} \sigma \tau \rho o \lambda o \gamma i \alpha$ denote 'astronomy' (Ptolemy 1964: ix).

The outlines of western astrology already materialized in ancient times (Tester 1987: 11), with the Greek background (Barton 1994: 21) and Egyptian traditions (Lindsay 1971: 153-180) playing an important role. Most of it, however, developed in Hellenic Egypt and Rome. Claudius Ptolemy (1964) has gathered and systematised Alexandrian astrology. Early Roman astrology is first and foremost associated with Marcus Manilius (Hübner 1982) and Dorotheos (Nikula 1993: 56), the later period with Vettius Valens (Tester 1987: 45), and the final period with Firmicus Maternus (Bram 1975: 4-7; Knappich 1967: 74). Hubert Korsch (1935) has summarised the known connections of prominent figures of antiquity with astrology.

In its final form, ancient astrology is a product of the Hellenic era: it was affected by different cultures, since the conquests of the Macedonians induced an active cultural exchange between the regions of Mesopotamia, Egypt, Greece, and Iran. All authors have agreed that while other cultures have merely supplemented it, the main principles, ideology, and basic methods of astrology still originate in Mesopotamia, although its contribution to the doctrine that had developed by the end of antiquity has often been underestimated (Boll 1926: 1-2).

According to Ptolemy the astrologer must be a man that knows accurately the movements of all the stars, the sun, and the moon, so that neither the place nor the time of any of their configurations (Ptolemy Tetrabiblos I.2, 1964: 10-11). Ptolemy uses the notion $\dot{\alpha} \sigma \tau \varepsilon \dot{\varepsilon} \omega \nu$ 'stars' to designate planets rather than fixed stars. The astrologer's work can be roughly divided into two parts. First the astrologer needs to gather the astronomic material relevant to the task (for example, foretelling the country's future, calculating birth or congruity horoscopes, predictions for specific persons about specific moments in the future, etc.). Then he must interpret the acquired material. And only the interpreted and commented product will become astrological. 
The main astronomical components of astrology are astrological planets, signs of the zodiac, and astrological houses, which have all developed and changed in the course of time. Information on the development of all the main astrological components, except for the system of houses, which is of more recent origin, is described in Mesopotamian texts (Neugebauer \& van Hoesen 1959: 7-8). The early history of astrology was therefore written primarily in Mesopotamia.

\section{THE EARLY HISTORY OF ASTROLOGY}

Astrology was by no means the only method of prediction in Mesopotamia, where the art of foretelling, often interrelated with healing magic, was regarded very favourably. The future was read from the condition of animal livers, by considering eclipses, from atmospheric phenomena, the migration of birds, etc. In this sense the culture located between the Tigris and Euphrates was not unique using livers and bird migration for foretelling the future was also characteristic of the Etruscans and the Romans. Astrology, however, has at least three important advantages over all other arts of prediction - the divine nature of stars, the universality of celestial phenomena and the fact that these phenomena could be forecasted.

Similarly to the history of Mesopotamian astronomy that can be divided into three distinctive periods (Neugebauer 1975: I 2), Mesopotamian astrology also passed through three periods of development: (i) early or augury astrology, (ii) primitive zodiacal astrology and (iii) horoscopic astrology (van der Waerden 1991: 184). As the history of Mesopotamia is very long and complex, it is important to know the specific period or location on which the statement is based, otherwise it is easy to come to wrong conclusions. If we make generalisations over the whole history of Mesopotamia, it would be virtually impossible to analyse, say, the names of planets (Brown 2000: 53; Kasak \& Veede 2000: 1244).

A prophecy written on the 2nd millennium BC says: If a child were born on the twelfth month, it would live long and bear many children. Although the prophecy shares a striking similarity to the daily horoscopes published in today's newspapers, it is still an example of primitive prediction rather than astrology proper. In the course of 
time astrology transcended all other methods of prediction, due to the Old Babylonian astral religion, the universality of celestial phenomena as omens, and the ability to forecast. Babylonian astrologers knew how to compile birth horoscopes but the technique was elaborated in the later period. The system of astrological houses and zodiac symbols does not originate in Babylonia, although in the period of horoscopic astrology certain divisions of the ecliptic-signs of the zodiac - gradually began to replace constellations. Whether it was inspired by Egyptian influence or devised by the Chaldeans themselves is still uncertain.

Early astrology was practiced in the Assyro-Babylonian or Akkadian period of astral religion. From this period we know the extant omen series called Enūma Anu Enlil, the original version of which is dated to the 2 nd millennium BC, although it was also actively practised under the rule of King Ashurbanipal. In early astrology, predictions were made through different omens. Observing eclipses, for example, was of great importance. In the Assyrian Era, eclipses could already be forecasted. Numerous tablets of Assyrian astrologers' reports to the king, containing a thorough description of the observation and planets seen during the eclipse, and how the obscuration shifted, have been preserved to the present day. Different areas of the moon were associated with geographical locations, which meant that it may have been possible to attribute the misfortune predicted by the eclipse to the neighbouring country instead.

On the 14th day the moon will make an eclipse. It (predicts) evil for Elam and the Westland, good for the king my lord. Let the king my lord be happy. (Hunger 1992: 388: 222).

In Adar (XII) on the 14th day the moon will make an eclipse. If the moon makes an eclipse in Adar (XII) on the 14th day in the evening watch, it gives its decision for the king of the world, for Ur and the Westland. [---] If the moon will make an eclipse in Adar (XII): the king of Elam (will die). (Hunger 1992: 250: 138).

Next to the weather, cloudlessness and wind, it was also important to consider the alignment and relative movement of planets during the eclipse: 
If Jupiter stands inside the moon, in this year the king will die; variant: there will be an eclipse of the moon and Sun; a great king will die. [---] If Jupiter enters the moon: there will be famine in the Westland; the King of Elam will fall in battle; in Subartu a noble will revolt against his lord. (Hunger 1992, 100: 60)

Analogous prediction to the court and the king was also practised in the Late Babylonian period, though in this period new tendencies began to emerge. The conviction that earthly occurrences were the aftermath of celestial phenomena was widespread.

Primitive zodiacal astrology developed in the state of Chaldaea or Late Babylonia that emerged after the destruction of Assyria by the Babylonians in alliance with the Medes. The impact of Zurvanism, the predecessor of contemporary Iranian religions, the cult of Mitra, and Zoroastrism on Babylonia was immense. According to Zurvanism everything that happens in the world is predestined by eternal time (Time God Zurvan, the ancestral being of everything in the world). Stars function as indicators of predetermination. When the stars assume their original position at the end of the "great year", all events to the smallest detail will recur. This doctrine has also been called astral fatalism (van der Waerden 1991: 169-171). Even Greek philosophy contains traces of this doctrine. Pythagoras has argued that everything that has ever happened will recur at a predetermined time in the future and is not utterly new. According to the Stoic philosophy the world will be destroyed by fire when all planets have returned to their original position and a new world will emerge. In his book Anthropologia Nemesios Emesenos, the clerical figure and philosopher in the Early Byzantine Empire, claimed that as long as stars follow their usual course, everything will recur exactly as it happened even in the smallest detail. Heraclitus believed that the great year lasted for 18,000 years, whereas the Stoics, as Simplikios has written, considered it 360 times longer.

He who has seen present things has seen all, both everything which has taken place from all eternity and everything which will be for time without end; for all things are of one kin and of one form (Marcus Aurelius. Meditations. VI, 37) 
It is extremely important to bear in mind that according to this idea the stars are not the cause of events, their movement is something like the movement of the hands of a clock, which indicate the time when a given event will occur, but do not cause the event. The relation between cause and effect is universal and irrevocable. Astrologers can foretell future events from the signs.

The astronomic text MULAPIN describes constellations on the Moon's path - the gods that stand on his way and whose territory the Moon passes every month. The list of 18 such constellations is proof that actual constellations, not zodiac signs, were meant. Later, when zodiac astrology came into use, the ecliptic was divided into sections of equal length that included the constellation of the same name, or at least part of it. Foretelling was based on the movement of the Moon and the planets relative to zodiac signs. Although, in texts, astrological constellation and zodiac sign names were sometimes used simultaneously, a saying "At the beginning of the Nisan month Jupiter and Venus are at the beginning of Gemini" can only be interpreted astrologically (Lindsay 1971: 54-55, 57).

For example the size of the crop harvest was predicted by the Moon's position relative to a zodiac sign on the day of Sirius's heliacal rise. Since the Sun moves counter-clockwise relative to the starts, a star on the day of its heliacal rise is visible for a moment just before dawn. The heliacal rise of Sirius was used in Egypt to predict the beginning of the Nile's flooding. This example seems to support the opinion that dividing the ecliptic into sections of equal length may be a result of Egyptian influence. Assyria's conquest of Egypt brought these big cultures into direct contact. There were also strong ties between Chaldea and Egypt, although relations were not always friendly. In Egypt, however, the ecliptic was divided into 36 segments, each holding the Sun for 10 days. 3 segments made up approximately one lunar month and also one twelfth of the ecliptic.

Zodiacal astrology demanded much more of astronomy than predicting astrology had. This was the beginning of diligent Moon-watching and elaboration of the cycles of the planets. Knowledge emerged that could be used to indirectly calculate the position of the planets and the Moon - this came in handy later in compiling birth horoscopes, since a child could also be born during the day or on a cloudy night. 
Horoscopic astrology appeared in Mesopotamia during the Persian occupation. At that time, mazdaism was the predominant religion in Iran. According to mazdaism, the world was created by the highest of the gods, the personification of goodness and lightAhura Mazdah. The personification of darkness and evilAngra Mainju or Ahriman causes trouble in the world of humans but will eventually be defeated.

Persian influence can also be observed in the works of Greek authors. Plato's dialogue Phaidros is clearly connected with astrology: in the sky there are Zeus and eleven main gods on war chariots, with them a heavenly army of gods and demons followed by the souls of people preaching to them. The souls that fall down will in their earthly life follow the same gods as they did in heaven. This indicates that the position of the planets at a child's birth determines the qualities of the soul that settles in the child's body, thus also his or her fate (van der Waerden 1991: 160-161). The cult of Mitra the Sun God gave later special meaning to the sign in which the Sun was at the moment of birth; this tendency was further reinforced by Egyptian influence. Nevertheless, in the early Mesopotamian period, the zodiac had not yet acquired the same importance that it had in Hellenic astrology.

However, there seems to have been a quite practical reason for the beginning of the making of birth horoscopes - since the Persian conquerers had no need of the services of the Babylonian astrologists, the astrologists had to find another way to earn a living. Indirect data gives us reason to believe that horoscopes came into use ca $450 \mathrm{BC}$ and soon spread to Greece.

The first known cuneiform horoscope comes from $410 \mathrm{BC}$ and the latest from 69 BC (Rochberg 1998: 3-4). The Babylonian birth horoscope predicts a child's future and character, and the course of their life from the positions of planets at the moment of birth. This was actually usually based on the moment of the beginning of sunset of the day preceding birth (since Babylonians, as many other peoples using the lunar calendar, counted the start of a day from sunset). Later, time of birth was determined within a quarter of a day, or 6 hours. 
The best known old horoscope describes the sky on April 29, 410 BC. The text is translated as follows:

Nisannu, night of the 14th(?), ... son of Šumu-usur, Šumu-iddina, descendant [---], was born. At that time the moon was below the Pincer of the Scorpion, Jupiter in Pisces, venus in Taurus, Saturn in Cancer, Mars in Gemini. Mercury, which had set was not vis[ible]. [---] (Things?) will be propitious for you. (Rochberg 1998: 56)

Predictions tend to be general, mainly concerning character, and concrete predictions were avoided. Early horoscopes also include pseudo-horoscopic predictions mainly in connection with eclipses:

[---] (If) a child is born and during his infancy a solar eclipse occurs: He will die in a foreign city and the house of his father will be scattered. (Rochberg 1998: 14)

As a rule, horoscopic predictions are positive. If it is predicted that a child will not become rich, a way is still found to bring becoming rich into the prediction.

In time the positions of planets became increasingly important and they were marked more precisely relative to the zodiac. For example in a horoscope from $235 \mathrm{BC}$, the positions of all planets are marked in relation to the zodiac to an accuracy of one degree (Rochberg 1998: 84-85). In fact, planets were the most powerful element in Babylonian astrology. Horoscopes also considered the relative positions of the planets, especially their relation with the Sun. What in Hellenic times was the teaching about the domination and exile of planets probably started out as the Babylonian concept of a planet's secret home - the zodiac sign in which a planet is located, giving it additional influence.

In Chaldean horoscopes the formation of the essential elements of astrology, except the system of houses and the importance of the sign, which both are of later origin, can be observed well. It is true that astrology has a long history, but there is no proof in the history of Mesopotamian astrology to back up the assertions that the effects of the signs and planets were discovered during long-term ob- 
servations. Instead, one can observe the combination and adjustment of birth horoscopes according to the needs of the time.

A flexible interpretation develops first, and only then the rules and framework for composing a horoscope are formed. In Mesopotamian horoscopes elements that later fell into disuse were considered important - for example phases of the moon and time of the next lunar eclipse were taken into consideration.

Even though astrology developed during the Hellenic period, its ideology was already formed during the Mesopotamian period; later development was rather a refinement of details. Apparently there is no reason to doubt that the modern pseudo-science of the same name is based on its antique predecessor. Many other pseudo-sciences have borrowed their method from astrology - for example many horoscopes were compiled that were not based on the starry sky, numerology developed, telling fortunes by cards, etc. In the first step all these disciplines use techniques that can be compared to computational or data gathering and processing techniques, and which are claimed to be scientific. In the next step the product will be interpreted prognostically, using more or less inflexible algorithms. The manner of interpretering also plays an important role. This makes ancient astrology one of the main roots of pseudo-sciences, especially those based on formal rationalism - prediction is derived from effects that must be physically determined, but cannot be proved by a scientific method.

\section{ELEMENTS OF SCIENTIFIC THINKING IN ANCIENT GREEK PHILOSOPHY, ASTRONOMY AND COSMOLOGY}

We may notice the process of mythic thinking changing into philosophic and scientific thinking in ancient Greece. The fall of the mythic world can be seen in epics that have preserved.

In Iliad and Odyssey, Homer uses comparison, which is not a mythic but already a poetical method. The way Homer describes the deeds of the gods, their quarrels, their amorous adventures, shows that the basis of mythic thinking - trustful belief in myth, is hardly characteristic to a poet. Homer does not raise the question of how the world came into being. Hesiod, who started systemising gods and 
myths by describing the beginning of the world in his Theogony, does that. With this the basis of the mythic world was torn apart. Hesiod's gods are connected with each other and have somehow come into being and have developed. His gods are personalised forces (elements) of nature and have emerged due to some historical process. In the beginning there is Chaos, which is not the absolute antithesis of order, the meaning of the word as it is used in contemporary mathematics. Comparing the understanding of Hesiod and that of the Ionic philosophers about how the World came into being, one can see that these conceptions are very similar, the elements can be compared on a one-to-one basis.

\begin{tabular}{|l|l|l|} 
Hesiod & Anaximander & Anaximenes \\
\hline Chaos & $\begin{array}{l}\text { Arhce (primary } \\
\text { substance) }\end{array}$ & Air \\
\hline Eros & $\begin{array}{l}\text { Separation of cold } \\
\text { and warm }\end{array}$ & $\begin{array}{l}\text { Thickening and } \\
\text { thinning }\end{array}$ \\
\hline Earth (Gaia) and Tartaros & Earth and air & Earth and air \\
\hline Night and Day & The sphere of fire & \\
\hline Sky (Uranos) from Gaia & Celestial bodies & $\begin{array}{l}\text { Celestial bodies } \\
\text { (from Earth) }\end{array}$ \\
\hline Mountains, seas, ocean & Sea (from ocean) & Sea \\
\hline
\end{tabular}

Table 1. The comparison of the beginnings of the world (Kessidi 1972: 121).

Hesiod takes a long step towards the philosophical way of thinking. Thales of Miletus was the first to give up the mythic interpretation of the world for the philosophic one. According to him the source of being is in reality itself, nature, not in something supernatural, something outside nature. Water is the beginning of everything, endless matter, which is in eternal movement. Everything can be formed and destroyed, but the primary substance is stable and eternal.

Anaximander of Miletus did not consider any element to be primary. His primary substance is an abstract original matter, which is endless, indefinite $\ddot{\alpha} \pi \varepsilon \imath \rho o v$ (apeiron). 
It will be a serious mistake to take it for some primary material of which everything is put together as the modern man accepts and understands it (Moore 1991: 17). The word $\delta$ ó $\pi \varepsilon \imath \rho \circ \zeta$ in Greek means 'boundless', 'endless', 'infinite', 'countless', etc. (secondary meaning is 'inexperienced', 'incompetent', 'profane'). This word is in opposition to the word $\tau o$ c $\pi \varepsilon ́ \rho \alpha \varsigma$, which means 'limit', 'bound', 'edge', 'border', 'end' etc. In his cosmology Anaximander contrasts definable with indefinable. For the Greeks $\tau o$ í $\tilde{\varepsilon} \rho \alpha \varsigma$ was something they could understand. The word had a positive meaning compared to $\tau o ́$ ó $\pi \varepsilon \imath \rho o v$, which was something that was not understandable, that was awful and negative. Tó $\ddot{\alpha} \pi \varepsilon i \rho o v$ is the place where everything that exists resides, being at the same time an opposite to itself. It is by this that the transition from being something to negation of the same takes place, for example from cold to hot. According toAnaximander, things do not form from the qualitative change of an element, but due to the separation of the opposites which is caused by eternal movement. We do not know if it is possible to interpret $\tau o$ ó $\pi \varepsilon \imath \rho o v$ as 'matter', if it is spatial, if it is mathematically infinite, but we do know that it is the indefinable, indeterminable that surrounds us. The existing can exist by being $\tau o ́$ $\pi \varepsilon \rho_{\rho} \alpha \varsigma$, but its beginning and end is $\tau o ́$ ó $\pi \varepsilon i \rho o v$.

The philosophy of Pythagoras is based on the concept of numbers as an ideal object. There is not much known about his cosmogony; something might have preserved through Philolaus. It may be possible that the idea of a spherical Earth and heavenly bodies comes from Pythagoras. More important is his teaching of soul, which has been influenced by the religion of Iran and Mesopotamia, and through which the ideology that favoured the astrological way of thinking started to spread in Greek culture.

Herakleitus of Ephesus considers fire as the primary substance. From fire there will come water, earth, air and fire again. Fire is changing, the world is changing, and there is nothing stable in it. The idea that the Earth rotates and the principle of the temporal infinitude of the Universe originate from Herakleitus.

It is definitely known that Parmenides of Elea considered the Earth spherical. He was the first to discover that the morning star and the evening star were the same. Yet he did not consider this knowledge as important as knowledge in philosophy. Parmenides discov- 
ered the difference between reason and mind and pointed out the distinction between truth and opinion. According to his main point of view there is only one eternal existence - identical with itself, changeless, invariable, stationary, constant. Reality is a single, unchanging whole. So thought also his student Zeno of Elea. He demonstrated that the common-sense belief in the existence of "the many" or in motion also leads to paradoxes. It is interesting to note that logical consequences are for Parmenides and for Zeno more important than empirical facts.

Plato's cosmology is interesting and complicated but very mythical too. The same cosmological model is described in dialogues Republic and Timaeus. The World consists of eight concentric spheres on the same shaft and they all rotate with different velocities. The outer sphere is for fixed stars and others for planets. The Earth lies at the centre of the spheres. From Earth all the spheres seem to be one common surface (Republic 616b-617b).

In Timaeus we find the same model connected to the soul of the world. The material of soul is mixed and given the appropriate mathematical structure using different movements of stars and planets. The outer sphere for fixed stars is the circle of "Same", the others, for the planets are in the circle of "Different". A human's ability to see similarities means that his soul is in rotation synchronised with the "Same" rotation of the soul of the world. Therefore a human's ability to see differences means that his soul is in rotation synchronised with the "Different" rotation of the soul of the world (Timaeus 31-37).

In both dialogues reasons for the movements of spheres are described. More information can be found in Republic. There are three Fates, daughters of Necessity, Lachesis, Clotho and Atropos. Clotho (things of present) helps turn the sphere of the "Same". Atropos (things to come) helps turn the spheres of the "Different" they all rotate much slower, like the outer sphere. Lachesis (things of past) causes retrograde movement of planets. Different speeds of planets e.g. far from the Sun and close to the Sun is explicable by weakening of impetus (Republic 617c-e)

According to Plato our world is unique and the sphere of fixed stars is its boundary. If all things exist inside the boundary may we ask 
what is outside? Later, this was used as a place for the transcendent or other world. In the medieval period it was quite a popular idea to put paradise outside the sphere of fixed stars. Such a point of view splits the Universe into two different regions.

Plato's model corresponded to observational astronomy in his time but only qualitatively. More important was its philosophical and mythical subject.

Eudoxus of Cnidus discarded mythical explanations and used only geometrical arguments for the movement of planets. This is the real beginning of scientific astronomy. To explain retrograde movement he used a set of interconnected spheres. In spite of several problems it was an important result of theoretical thinking. Aristotle later used his ideas.

Aristotle used Eudoxus's model of the Universe but he needed 55 spheres in order to account for current astronomical observations. The movement of planets is easily explicable by the Aristotelian theory of five elements. Four of the elements are terrestrial or sublunar. Two of them - fire and air- are light, their natural tendency is to flee away from the centre of the Universe and they move upward. Two terrestrial elements - earth and water - are heavy. Their natural tendency is to fall down, as near as possible to the centre of the Universe. But from the Moon sphere outwards the Universe consists of the fifth element, whose natural motion is circular. This whole explanation is elegant, but then we must abandon the principle of the unity of all substances in the Universe. In spite of that, astronomy as scientific discipline can be considered as the most important result of Eudoxus's and Aristotelian works. After them, the development of scientific astronomy can be treated as working on details, but the method has roughly remained the same: to observe, to fit the results in demythologized theory and later on to check the theory against observations. 


\section{THE INFLUENCE OF ASTROLOGY IN ANCIENT GREECE ON SCIENTIFIC THINKING}

Mesopotamia has influenced Greek culture more than was previously thought (West 1999: 10-33). That includes astronomy and astrology as illustrated by the table 2 .

On a closer look it appears that this is true of the names of the Zodiacal and near to Zodiac constellations, but not without exceptions (Koch 1989: 111-112; Rochberg 1998: 29-30). The constellations that are closer to the North Pole e.g. Ursa Major and Ursa Minor, have different names. Instead of Perseus this constellation was called 'Old Man' in Mesopotamia and Orion was named 'The Shepherd of the Skies'. Some constellations in the same regions of the starry sky were totally different. The northern part of Aquarius and half of Pegasus formed the constellation that was named 'Swallow' in Mesopotamia (Kugler 1913: 5-11). Despite the common opinion that Libra was formed in honour of Julius Caesar (Allen 1963: 271), table 1 shows that Libra is a much older constellation. This fact was also known to Kugler (1913: 10-17).

Since astrology primarily uses the constellations in the Zodiac, we can tell that the names of the constellations connected with astrology moved from Mesopotamia to Greece without any great changes. The names of other constellations changed much more.

At the end of the archaic period of Greek history there was more astronomy and less astrology. The starry sky held an importance mainly for farmers and sailors. There was no astral religion in Greece and no sign of star cult. It is reasonably certain that astrological thinking has not evolved on the spot but has been imported from Mesopotamia through Asia Minor and Egypt. The Greeks themselves assert that their astrology has Babylonian origins through many sources, and the most important of them is Chaldean Berosus (Bel usur).

Astrology elicited great interest in Greece, because compared to other future telling it seemed more rational. This was probably one of the reasons why astrology underwent a revival in the 20th century. 


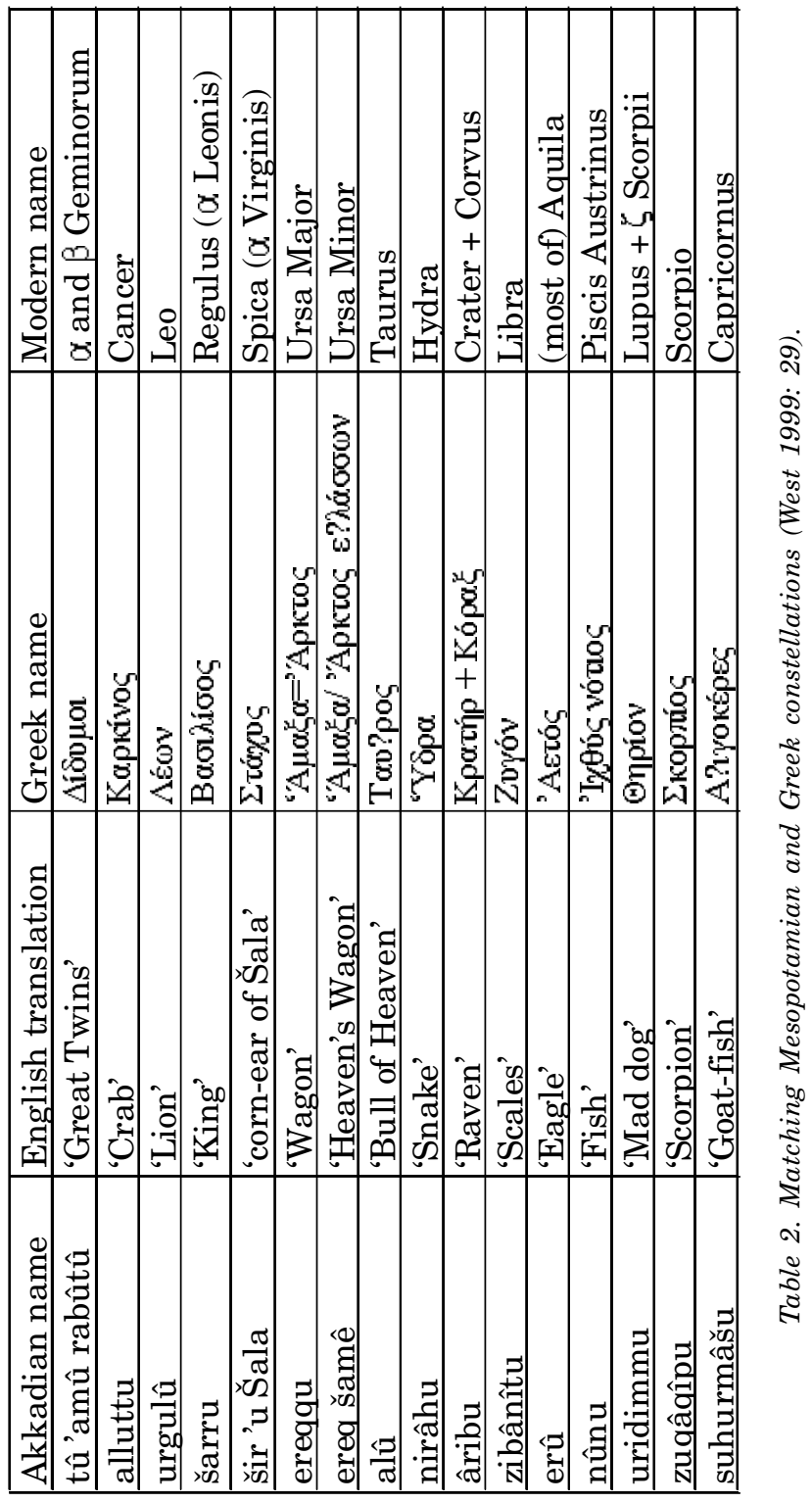


Astrological ideas influenced Zeno of Citium, the founder of Stoicism. According to Stoic philosophy the human being is a microcosm, which is coherent with macrocosm. Greek poet Aratus, who has written two astronomical and two astrological poems made those ideas widely known. Hellenistic tradition adopted astrology from Chaldea in first century B.C.

Even though there have been references to earlier Greek horoscopes (as early as 72 BC) the first Greek horoscope written on papyrus dates back to 10 BC (Neugebauer \& van Hoesen 1959: 161).

In the third century BC, around the same time that Berosus taught in his own school of astrology on Cos island, Aristarchus pondered on heliocentric cosmology, having previously demonstrated that the Sun is much bigger than the Earth. The astronomers Aristillus and Timoharis worked in the Great Library of Alexandria, surronded by half a million manuscripts. Their results were used by Apollonius to create his theory of epicycles.

Ancient scientists sought more for universal philosophical truths than for scientific facts in the modern day sense. But astronomy was an exception. While natural sciences dealt with general principles, astronomy and astrology had the purpose of "saving" events. It meant that astrologers (astronomers) had to be able to predict the time and place of star configurations and had to know their possible consequences, bad or good. Astronomical predictions could be verified with observations, but astrological interpretation allowed astrologers to prevaricate. It is not an exaggeration to say that astronomy/astrology in ancient Greece were the most scientific disciplines in a modern sense. Even so, one must not over-estimate the authority of astrology and astronomy. Astronomy was considered only to attend to "saving" events, while philosophers had to find the truth, which seemed more important to contemporary people.

In the period of zodiacal astrology it was a quite normal belief that terrestrial events happen due to celestial ones. It is very plausible, that a confiding belief in causality is evoked by astrological influences. In contemporary science we can observe a strong belief in causality, as in ancient philosophy. It is possible that one of the main principles of science emerged and developed under the auspices of astrology. 
With the emergence of critical thinking in Greek culture, despite its seeming rationality, astrology became subject to criticism, too. The first known active critic of astrology was the philosopher Carneades. However, it appears that criticism ceased when Greece came under Roman rule in the same century. The Roman world view was fairly uncritical and full of omens, making astrology easily acceptable for them.

Similary worthy of attention is the faith in causalistic relationships in antique philosophy and science. Nobody asks, for example, what gives causality the right to be causalistic. As noted before, in the period of astral fatalism omens were treated as phenomena that are observed by the wise but which in themselves do not cause the predicted event. In the period of zodiacal astrology, however, heavenly events are interpreted as directly causing earthly developments. It is highly possible that from there stems the causality that can be found in both antique philosophy and contemporary science. Thus it is possible that causality, one of the foundation stones of modern sciences, has emerged and developed under astrology.

The importance of astrology in ancient times is best illustrated by the work of Claudius Ptolemy, who has been considered the most influential astronomer and astrologer of antiquity. Ptolemy lived and worked in Alexandria in the 2nd century AD. Although astronomy and astrology at that time were not used as separate terms, Ptolemy made a clear distinction between the two terms and wrote a separate book on each topic. His famous Almagest ( $\dot{\eta} M \alpha \theta \eta \mu \alpha \tau \iota \kappa \dot{\eta}$ $\Sigma v v \tau \alpha \xi ı)$ largely covers the contemporary understanding of astronomy and was the most influential book of astronomy in the 15th century. The author however considered it an astronomical introduction to the main book - the astrological Tetrabiblos or the

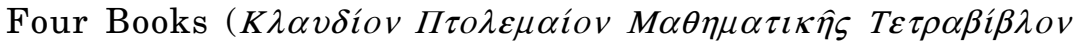
$\Sigma v v \tau \alpha ́ \xi \varepsilon \omega \varsigma)$. Modern research has indicated that inAlmagest Ptolemy relied on the works of Hipparchus, who had lived three centuries before him, which he then intentionally skewed to fit his purpose, often doctoring results and describing observations that could not have existed (Newton 1978). It was all for the sake of the astrological truth that he attempted to describe in Tetrabiblos. While Ptolemy's astronomical and cosmological views are quite well known even today, we know far less of his work in astrology. There, as well 
as in astronomy, Ptolemy was a systemiser rather than an inventor - his work could be compared with that of Vettius Valens, but was far more comprehensive and gained more fame and prestige. Characteristically of this period the text does not include references, therefore it is impossible to distinguish between the summary of previous studies and the author's own contribution.

In Tetrabiblos Ptolemy also attempts to maintain the scientific approach, trying to avoid lapses into mysticism or divine intervention. In the first book of Tetrabiblos he observes astrology from the technical aspect, dividing it in two: universal astrology (e.g. astrogeography) and personal astrology (e.g. medical or horoscopic astrology). The second book deals with universal astrology, the third and fourth book with personal astrology. The two last books are divided in three parts: discussing a) birth omens, b) the moment of birth and c) what happens after birth.

\section{CONCLUSION}

Ancient astrology has always been and still is the moral pillar of various pseudo-sciences. Astrology is the key to understanding the nature of pseudo-sciences, either for purposes of criticism or for seeking traces of rationality in them. In addition to the aforementioned, the analysis of pseudo-sciences enables us to study human thought and may offer new opportunities to define scientific conviction. Sometimes it would be practical to disregard the stereotype that scientific reasoning is the only way to acquire trustworthy information. More efficient definition of scientific conviction would provide new approaches in the critique of pseudo-sciences and would enable the criticism of scientific ideologists for their vague evasion of pseudo-sciences, which paradoxically may lead to pseudo-scientific tendencies in practical science.

A closer look at the subject somewhat unexpectedly reveals that compared to other ancient practices ancient astrology complies more closely with modern scientific requirements. Some important scientific paradigms may in fact prove to originate in astrology. Considering this, we should not condone the practice of separating the history of astronomy and the history of astrology, as it is not in accordance with the principle of scientific objectivity nor the con- 
victions of the authors, as both Lynn Thorndike (1929: 3-4) and Paul Feyerabend (1975) have warned. It appears that if we also took ancient astrology in consideration, the history of astronomy and of science in general would raise fewer question marks. The history of astronomy does not need to be revised and the lack of censorship will certainly not deprive it of its scientific dignity.

Translated by Kait Realo et al.

\section{References}

Allen, R. H. 1963. Star Names, Their Lore and Meaning. New-York: Dover Publications.

Barton, T. 1994.Ancient astrology. London \& New-York: Routledge.

Boll, F. 1926. Sternglaube und Sterndeutung. Leipzig \& Berlin: B. G. Teubner.

Bram, J. R. 1975.Ancient Astrology Theory and Practice. Matheseos Libri VIII by Firmicus Maternus. Translated by J. R. Bram. New Jersey.

Brown, D. 2000. Mesopotamian Planetary Astronomy-astrology. Cuneiform monographs 18. Groningen: STYX.

Feyerabend, P. 1975. Against Method. Outline of an anarchistic theory of knowledge. London: New Left Books.

Hunger, H. 1992. Astrological Reports to Assyrian Kings. Helsinki.

Hübner, W. 1982. Die Eigenschaften der Tierkreiszeichen in der Antike. Wiesbaden.

Knappich, W. 1967. Geschichte der Astrologie. Frankfurt am Main.

Kasak, E. \& Veede, R. 2000. Mesopotaamia planeedinimedest [About Mesopotamian names of Planets, in Estonian]. Akadeemia, 6, pp 12231246.

Kessidi, F. H.Ot mifa k logosu [From Myth to Logos, in Russian]. Moskva: Mysl.

Koch, J. 1989.Neue Untersuchungen zur Topografie des babylonischen Fixsternhimmels. Wiesbaden: Otto Harrasowitz.

Korsch, H. 1935. Grundriss der Geschicte der Astrologie. Düsseldorf.

Kugler, F. X. 1913. Sternkunde und Sterndienst in Babel. Ergänzungen zum Ersten und Zweiten Buch. Münster.

Lindsay, J. 1971. Origins of Astrology. London.

Moore,A. W. 1991.The Infinite. London \& New-York: Routledge.

Neugebauer, O. 1975. A History of Ancient Mathematical Astronomy. Berlin, Heidelberg \& New-York: Springer-Verlag.

Neugebauer, O. \& van Hoesen, H. B. 1959. Greek Horoscopes. Philadelphia. 
Newton, R. R. 1978. The Crime of Claudius Ptolemy. Baltimore and London: The John Hopkins University Press.

Nikula, R. A. 1993. Astrologian Historia. Helsinki.

Ptolemy, C. 1964. Tetrabiblos. The Loeb Classical Library. Cambridge. Rochberg, F. 1998.Babylonian Horoscopes. Philadelphia.

Tester 1987 = Macmillan CompanyTester, S. J. A History of Western Astrology. Suffolk: The Boydell Press.

Thorndike, L. 1929. A History of Magic and Experimental Science. NewYork: Ferris.

van der Waerden, B. 1991.Science Awakening II. The Birth of Astronomy. (in Russian). Moskva: Nauka.

West, M. L. 1999. The East Face of Helicon. Oxford \& New-York: Oxford University Press. 
